\title{
Consumer Acceptability of Yoghurt Produced from fresh Cow milk using Brevibacterium linens as Starter Culture.
}

\author{
${ }^{* 1}$ Lawal, R. A., ${ }^{1}$ Musa, H. ${ }^{2}$ Adebusoye, M.S. \& ${ }^{1}$ Haruna, U.S. \\ 'Department of Food Science and Technology, Federal Polytechnic, Bauchi, Nigeria \\ 2Department of Nutrition and Dietetics, Federal Polytechnic, Bauchi. Nigeria \\ *Corresponding author's Email: motherofbelievers54@gmail.com
}

\begin{abstract}
This study was investigated consumer acceptability of yoghurt produced from fresh cow milk using Brevibacterium linens as starter culture. The fresh cow milk was collected from Vom, Jos, and Plateau State, Nigeria. Bervibacterium linens was isolated from sample of cheese. The milk samples were clarified to remove foreign materials, pasteurized at $65^{\circ} \mathrm{C}$ for $30 \mathrm{~min}$ to destroy pathogenic materials and later cool to temperature of $42^{\circ} \mathrm{C}$ and inoculated with Freeze- dried yoghurt starter as inoculums and allowed to ferment for 4 hrs. The semi- solid curds were homogenized; package and cool at $4^{\circ} \mathrm{C}$. Aroma, mouth- feel and taste were monitored for the sensory quality. The general acceptability of the products was evaluated using twenty (20) trained panelists. The result of the sensory evaluation of the yoghurts showed that the yoghurt produced from $B$. linens as starter culture was significantly different $(p<0.05)$ than those produced from common starter culture.
\end{abstract}

Keywords: Consumer Acceptability, Yoghurt, Fresh Cow Milk, Brevibacterium linens, Starter Culture.

Proceedings Reference Format

Lawal, R. A., Musa, H., Adebusoye, M.S \& Haruna, U.S1 (2021): Consumer Acceptability of Yoghurt Produced from fresh Cow milk using Brevibacterium linens as Starter Culture. Proceedings of the 27th iSTEAMS Multidisciplinary Innovations \& Technology Transfer (MINTT) Conference. Academic City University College, Accra, Ghana. June, 2021. Pp 425-4_www.isteams.net/ghana2021. DOI - https://doi.org/ 10.22624/AIMS/iSTEAMS-2021/N27P36

\section{INTRODUCTION}

Milk is a complex biological fluid secreted in the mammary glands of mammals. Its function is to meet the nutritional needs of neonates of the species from which the milk is derived. However, milk and dairy products form a significant part of the human diet. They are rich sources of nutrients such as proteins, fats, vitamins and minerals; ironically, it is because of this that these products are susceptible to rapid microbial growth. In some instances, this microbial growth may be beneficial, while in others it is undesirable. Dairy products are vulnerable to spoilage or contamination with pathogens or microbial toxins; therefore, the microbiology of milk products is of key interest to milk handlers and those in the dairy industry. Nigeria, with a population of more than 170 million is grossly underprovided with essential food components - particularly the milk protein. Reports indicate that cow provides essentially all the fluid milk consumed (lgwegbe et al., 2014); and that milk production has been nose diving or at best has remained constant since 1994 in the country. To ameliorate this problem of low-level protein intake, especially from cheap dairy sources, there is the need for concerted effort to bring about the massive production and utilization of protein based food items from milk of other animal species such as goat, and at competitive costs so that they would be affordable to the general masses. 


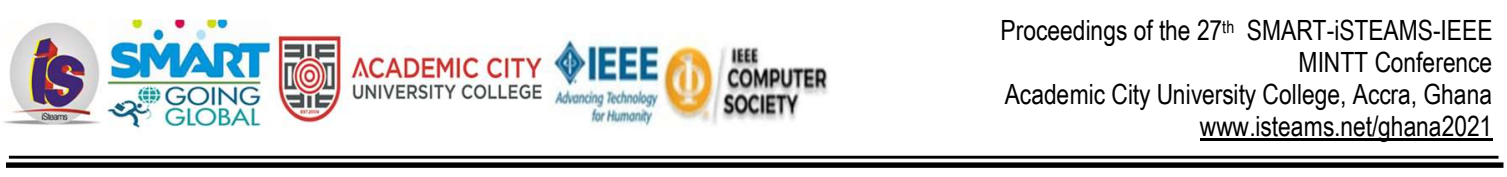

Yoghurt is one of the oldest fermented milk product consumed all over the world and it is produced by fermenting milk with lactic acid bacteria which responsible for development of typical yoghurt flavor. Fermentation is one of the oldest methods practiced by human beings for the transformation of milk into products with an extended shelf life Tammie and Robinson (1999). The conversion of lactose to lactic acid in fermented products has preservative effect on as the $\mathrm{pH}$ of cultured milk inhibits the growth putrefactive bacteria and other determined organisms, thereby prolonging the shelf life of products Esharaga, et al., (2011). Yoghurt is nutritionally rich in protein, minerals and vitamins and the values differ due to a number of reasons such as sources of milk, processing methods and ingredients used. Worldwide, cow's milk is most commonly used to make yogurt but milk from water buffalo, goats, sheep, camels and yake is also use various different part of the Castro, (2007).

Brevibacterium linens is non pathogenic and has long usage in food industries (Collins and Matthew, 2006). It has antimicrobial properties which can reduce the effect of pathogenic Listeriamonocytogenes by1-2 log units .This property makes it safer for human consumption (Motta and Brandelli, 2008). This antimicrobial property is known as bacteriocins. These are a kind of ribosomal synthesized antimicrobial peptides produced by bacteria, which can kill or inhibit bacterial strains closely-related or non-related to produced bacteria, but will not harm the bacteria themselves by specific immunity proteins. Bacteriocins become one of the weapons against microorganisms due to the specific characteristics of large diversity of structure and function, natural resource, and being stable to heat. Many recent studies have purified and identified bacteriocins for application in food technology, which aims to extend food preservation time, treat pathogen disease and cancer therapy, and maintain human health. Therefore, bacteriocins may become a potential drug candidate for replacing antibiotics in order to treat multiple drugs resistance pathogens in the future. Microbial communities from rinds of surface-ripened cheeses are composed of various bacteria, yeasts and molds, which contribute to the flavor, texture and appearance of the final products.

These microorganisms may come from the milk, the ripening environment or from ripening cultures that are widely used in the cheese industry. The function of the ripening cultures is to provide specific organoleptic properties, to ensure a better regularity of manufacturing, and to out compete pathogens or spoilage microorganisms (Motta and Brandlis, 2008). However, strains from ripening cultures frequently do not establish themselves in cheeses (Onranedt et al., 2003). Even if they are massively inoculated, these strains are sometimes out competed by the resident "house flora" due to insufficient fitness in the cheese surface habitat. The ability to grow on the cheese surface depends on various properties such as efficient salt tolerance and iron acquisition systems, or on the ability to use the energy compounds present in the cheese (Gavish, et al., 2004). In addition, growth is influenced by the other microorganisms present at the cheese surface, with which they may have positive or negative interactions. This study investigated the consumer acceptability of yoghurt produced from $B$. linens as starter culture

\section{MATERIAL AND METHODS}

\subsection{Source of milk and cheese}

The fresh cow milk used was obtained from National Veterinary Research Institute (Vom), Jos Plateau State, Nigeria. The cheese and standard starter culture (freeze-dried yoghurt starter) were obtained from food chemical shop in Jos. 


\subsection{Isolation of Brevibacterium linens from cheese}

Brevibactrium linens were isolated and characterized from cheese. Prior to isolation of Brevibacteriumlinens, cheese was thawed in the dark at $4{ }^{\circ} \mathrm{C}$. The smear was collected from cheese, by scraping the surface of the cheese and weighed. The culture was grown in $250 \mathrm{ml}$ Erlenmeyer flask containing $50 \mathrm{ml}$ of a medium composed of $20 \mathrm{~g} / \mathrm{L} \mathrm{D}$-glucose (Carloerba, London), $5 \mathrm{~g} / \mathrm{L}$ casamino acids (Difco), $1 \mathrm{~g} / \mathrm{L}$ yeast extracts (Biokar), $5 \mathrm{~g} / \mathrm{L} \mathrm{NaCl}$ and $1 \mathrm{~g} / \mathrm{L} \mathrm{KH}{ }_{2} \mathrm{PO} 4$. The $\mathrm{pH}$ was adjusted to 6.9 and the medium was sterilized at $121^{\circ} \mathrm{C}$ for 15 minutes and incubated at $25^{\circ} \mathrm{C}$ for 48 hours with stirring (150rpm) to oxygenate the medium (Galaup et al., 2005).

\subsection{Yoghurt production}

Yoghurt was manufactured using the method outlined by Tammine and Robinson (1999), with some modifications. The milk was filtered and clarified. The clarified cow milk was pasteurized at $65^{\circ} \mathrm{C}$ for $30 \mathrm{~min}$. Pasteurized milk samples were cooled to inoculation temperature of $42^{\circ} \mathrm{C} \pm 1{ }^{\circ} \mathrm{C}$ and then cooled samples were divided into two (2) portions; $A$ and $B$. Sample $A$ was inoculated with $2 \% v / v$ of $B$. linens starter the samples was fermented for $4-6 h$. The plain yoghurt was then packaged and stored. The same procedure was repeated for yoghurt inoculated with standard starter culture (freeze-dried yoghurt starter) consisting of Lactobacillus bulgaricus and Streptococcus thermophillus.

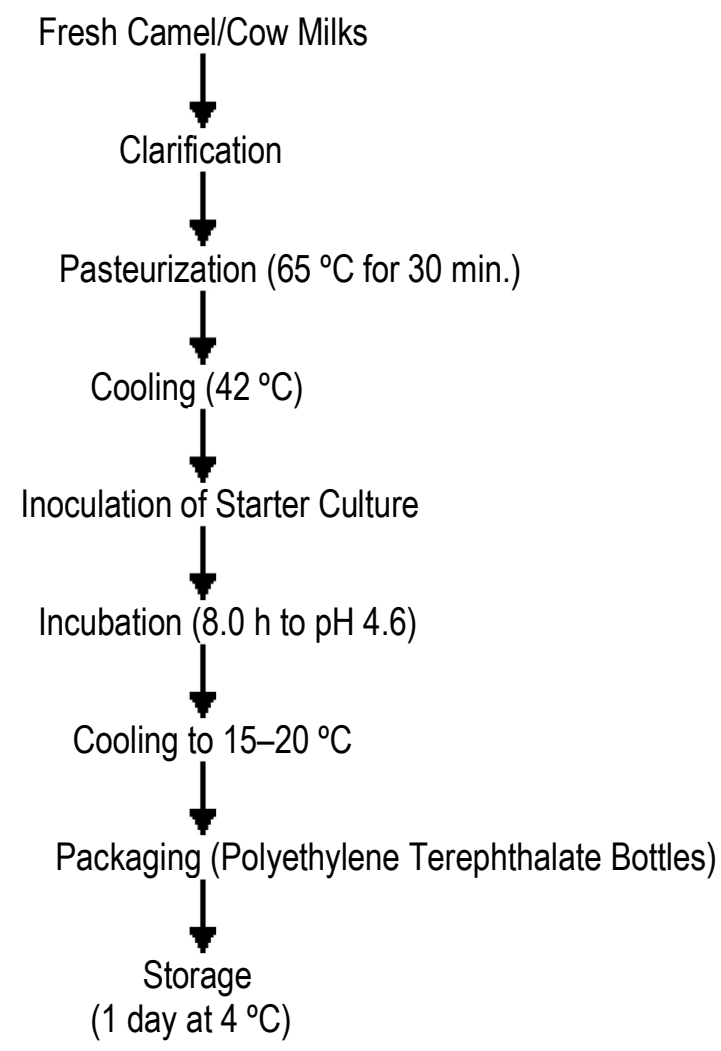

Figure1: Flow Chart for Modifying Method Yoghurts Production (Tamime and Robinson, 1999) 


\subsection{Sensory Quality Evaluation and Acceptability Test.}

Acceptance testing method described by Ihekoronye and Ngoddy, (1995) was used to investigate the acceptability of the yoghurt produced from Brevibacterium linens as starter culture against the common starter culture yoghurt. Determination of acceptability was done using 20 trained panelists who were familiar with yoghurt and were willing to participate, the panelist were recruited at Federal Polytechnic Bauchi. Briefing regarding the evaluation was given at the beginning of the session. Each panelist was assigned a number for identification purposes and he/she was responsible to evaluate two different samples. Samples were coded using a 3-digit random number and served successively. Panelists were asked to fill out a score sheet for each yoghurt sample they evaluated in term of taste, mouth feel, aroma and overall acceptability. Each sample attribute was rated using a nine-point Hedonic Scale. The nine points on the Hedonic Scale were: dislike extremely $=1$, dislike very much $=2$, dislike moderately $=3$, dislike slightly $=4$, neither like nor dislike $=5$, like slightly $=6$, like moderately $=7$, like very much $=8$ and like extremely $=9$. The average and mean values of scores for each of attributes was computed and analyzed statistically.

\subsection{Statistical Analysis}

The sensory analysis of the yoghurt samples was statistically evaluated using paired t-test.

\section{RESULT AND DISCUSSIONS}

The sensory assessment has judged by twenty (20) panelists was presented in table 3 . The sensory attribute of the yoghurt is a combination of the flavor, colour (appearance), taste and texture (the mouth feel). The scores for flavour, texture, colour, taste, and overall acceptability of yogurt produce from B.linens as starter culture was significantly $(P<0.05)$ lower than those produced from common starter culture. The low organoleptic properties of $B$.linens yogurt was attributed to many factors such as; high quantity of whey and fat hydrolysis during fermentation Gran et al., (1990). These made it to play a key role in cheese ripening and development of color pigment Arif et al.; (2006). This observation was in agreements with finding of lgwegbe et al., (2015). The appearance of the yoghurt is a combination of the colour and visual separation of the whey.

Table 3: Organoleptic properties of Yoghurt produced from B. linens and common Starter culture

\begin{tabular}{lll}
\hline Parameter & BLY & CSCY \\
\hline Taste & $5.06 \pm 0.01$ & 7.000 .02 \\
Flavor & $6.30 \pm 0.02$ & $7.14 \pm 0.01$ \\
Color & $6.50 \pm 0.04$ & $7.50 \pm 0.01$ \\
Texture & $6.20 \pm 0.01$ & $7.66 \pm 0.04$ \\
Overall acceptability & $6.01 \pm 0.02$ & $7.50 \pm 0.02$ \\
\hline
\end{tabular}

Means obtained from triplicate determinations $(p<0.05)$

Key:

BLY: Bevibacteriumlinens yoghurt

CSCY: Common starter culture yoghurt 


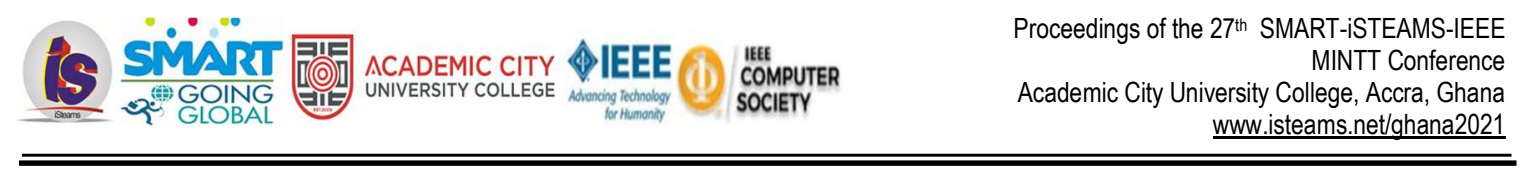

\section{CONCLUSION}

The result of this work revealed that the yoghurt produced from standard starter culture ingredient (L. bulgaricus and S.thermophilus) generally accepted by panelists than yoghurt produced B. linens

\section{REFERENCE}

1. Arfi, K., M.N., Leclereq-perlat, H.E., Spinnler, and P. Bonnarme (2005). Importance of the curd neutralizing yeast on the aromatic potential of Bervibacteria linens during cheese-ripening. Int. Dairy J.15:883-891.

2. Castro DJ (2007). Goats' milk is more beneficial to health than cows' milk: study suggests. Science Daily, Your source for the latest research news. July 31, 2007.

3. Collins, C.H and Kennedy, D.A. (1998). Laboratory- acquired infections (4th edition). ButterworthHeinemann, Boston, 48.

4. Eshraga A.Eissa, Abu Elgasim A. Yagoub, Efadil E, Babiker, Isam A, Mohamed Ahmed (2011). Physicochemical, Microbiological and Sensory Characteristics Of Yoghurt Produced From Camel Milk During Storage.

5. Galaup P, Flamin C, Carlet E and Dufosse L.(2005). HPLC analysis of the pigments produced by the microflora isolated from the 'Protected Designation of origin' French red-smear soft cheeses Munster, Epoisses, Reblochon and Livarot. Food Research International 58:855-860.

6. Gavrish, E. et al. (2004) Three new species of Brevibacteria-Brevibacterium antiquum sp nov., Brevibacterium aurantiacum sp nov. and Brevibacterium permense sp nov. Microbiology73, 176-183.

7. Ihekoronye, A. I. and Ngoddy, P. O. (1995). Integrated Food Science and Technology for the Tropics. Macmillan Publishers. pp 285. In Tamime and Robinson's Yoghurt: Science and Technology, 3rd Edition; Wood head Publishing Ltd., Cambridge, UK, pp. 11 - 118.

8. Igwegbe, A.O, Negbenebor, C.A, Chibuzo, E.C (2014). A comparative study on the fermen-tability of camel and cow"s milk by a symbiotic blends of lactic acid cultures. Scot. J. Arts Social Sci. Sci. Stud. 18(2):68-76.

9. Igwegbe,A.O. Maina, F.J. Kassum, A.L. Agbara,G.I. Chibuzo,E.C. Badau, M.H.(2015). Evaluation and acceptability of yoghurt drink processed from goat milk and a combination of goat and cow milks. Int. J. Biotechnol. Food Sci. 3(4): 41-48.

10. Motta.A.S and Brandelli.A (2008) Properties and antimicrobial activity of the smear surface cheese coryneform bacterium Bervibateriumlineus. Eur. Food Res Technol 227:1299-1306

11. Onraedt A, Soetaert W, Vandamme E. (2003). Industrial importance of the genus Brevibacterium. Biotechnol Lett. 2005;27:527-33.

12. Tamime, A. Y. and Robinson, R. K. (2000). Yoghurt: Science and Technology. $2^{\text {nd }}$ Edition, Wood head Publishing Ltd., Cambridge, UK, pp: 10 - 311. 